\title{
Paleoclimate Modelling Intercomparison Project
}

doi.org/10.22498/pages.29.2.63

Paleoclimate Modelling

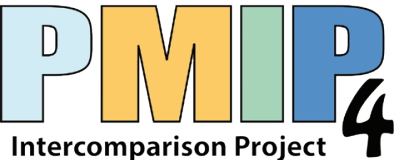

Paul J. Valdes' ${ }^{1}$ P. Braconnot ${ }^{2}$ and K.J. Meissner ${ }^{3}$

Thirty years is a long time in science. New data leads to revisions of old theories, and new theories challenge interpretations. Thirty years is a particularly long time in climate research, with huge advances in our understanding and ability to predict climate change and its impacts. Throughout this time, the Paleoclimate Modelling Intercomparison Project (PMIP) has been at the forefront of testing the latest generation of climate and Earth system models against paleoclimate data, acting as an important conduit between the paleodata community and the climate modelers involved in future projections. It has also acted as an important motivator of paleodatabase development, which is so essential for rigorous model-data comparisons.

Thirty years ago, the paleo community was quite divided between the scientists developing and collecting data and the paleoclimate modelers. Researchers collected paleoenvironmental data and developed interpretations of this data in terms of past climate, but many were somewhat suspicious of climate modelers, who seemed to sit in front of their computers and never go out into the field. The modelers confidently discussed the changes in climate around the globe for particular time periods of the past yet they could not calculate the uncertainty in their model results.
PMIP has changed all of this. By ensuring that modelers perform identical simulations, we can now quantify (some aspects) of the uncertainty intrinsic to climate models; by performing simulations with different boundary conditions, such as using alternative ice-sheet reconstructions, we can quantify uncertainties arising from a single source of interest. In the early days of PMIP, the climate models were often slightly older than the state of the art, but in recent years, PMIP modelers have been using the same models as those being used to support the IPCC assessments, ensuring that the lessons learned can directly inform future projections.

Similarly, PMIP has also helped bridge the divide between modelers and paleodata scientists. It is now common for both modelers and data collectors to work together to analyze model output and compare data, and it is increasingly common for members of the paleodata community to spend time in modeling labs and perform model simulations. Some modelers even spend time in the field! Such collaborations drive innovation, and some of the most exciting recent developments are in cross-over areas such as data assimilation.

This issue of Past Global Changes Magazine contains a range of contributions highlighting the amazing achievements of PMIP and the exciting new developments for the future. We hope you enjoy the read and the time spent with the growing PMIP model family.

Some of us have been lucky to have seen the full evolution of PMIP, attending the very first meeting in Paris involving about 40 research ers, to the latest workshop with more than 120 researchers of all nationalities and ages. The workshops have always been stunning in terms of the excitement in the science, and the enjoyable and lively discussions (and also the fun dancing and singing and dining which have become a tradition at these workshops). Future challenges and opportunities continue, with exciting developments including the use of Earth system models and the integration of transient simulations all ensuring that PMIP will continue to have a long and exciting future.

\section{AFFILIATIONS}

'School of Geographical Sciences, University of

Bristol, UK

2Laboratoire des Sciences du Climat et de

I'Environnement, LSCE/IPSL, UMR CEA-CNRS-UVSO,

Université Paris-Saclay, Gif sur Yvette, France

${ }^{3}$ Climate Change Research Centre, University of New

South Wales, Sydney, Australia

\section{CONTACT}

Paul Valdes: P.J.Valdes@bristol.ac.uk

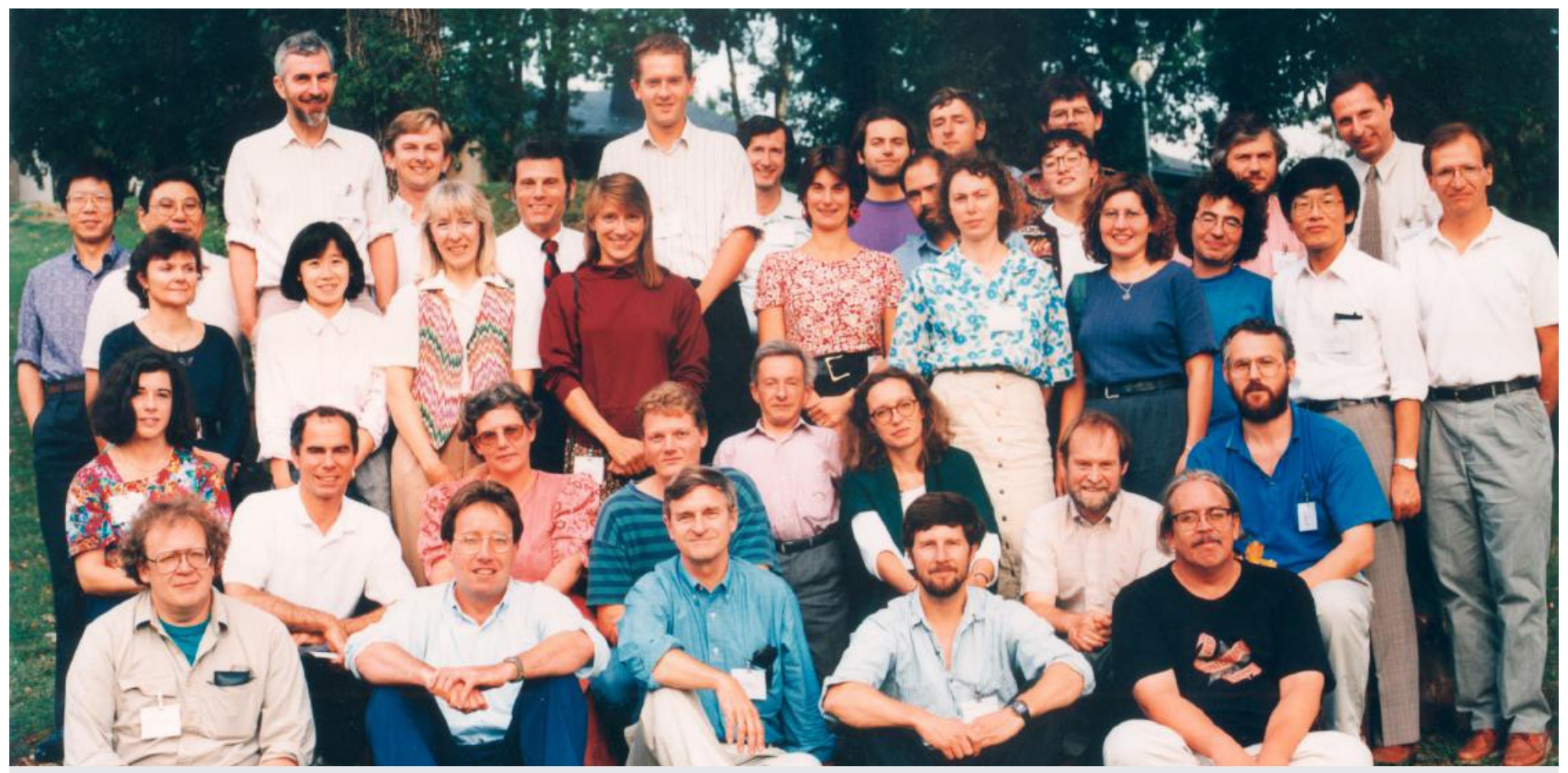

Figure 1: Participants at the PMIP workshop in Collonges-la-Rouge, France. Many are still involved in the PMIP community, though some are looking a lot older!

Front row: Pat Bartlein, Robin Webb (?), John Kutzbach, Dave Pollard, Bob Oglesby. Second row: Pascale Braconnot, Karl Taylor, Sandy Harrison, Gerhard Krinner, Klaus Herterich, Sylvie Joussaume, Norman MacFarlane, Jozef Sytkus. Third row: (?), Ayako Abe-Ouchi, Bette Otto-Bliesner, Lisa Sloan, Natalie de Noblet, Michael Lautenschlager (?), Marie-France Loutre, Masa Kageyama, Valerie Masson, Gilles Ramstein, Akio Kitoh, Tony Broccoli. Back row: Buwen Dong, Jai-Oh Oh (?), John Mitchell, Paul Valdes, Michael Schlesinger, Chris Hewitt, David Rind, Christophe Genthon (?), Alex Kislov, Dominique Jolly (?), Joel Guiot, Mikhail Verbitsky. Corrections and additions sent to pages@pages.unibe.ch are very welcome! 